\title{
Erratum to: Comparative Responses of Bermudagrass and Seashore Paspalum Cultivars Commonly Used in Egypt to Combat Salinity Stress
}

\author{
Mohamed Ahmed Shahba ${ }^{1,2^{*}}$ \\ ${ }^{I}$ Department of Horticulture and Landscape Architecture, Colorado State University, Fort Collins, CO 80523-1173, USA \\ ${ }^{2}$ Department of Natural Resources, Institute of African Research and Studies, Cairo University, Giza, 12613, Egypt \\ *Corresponding author: shahbam@lamar.colostate.edu
}

(C) Korean Society for Horticultural Science and Springer 2013

Erratum to: Hort. Environ. Biotechnol. 51(5):383-390. 2010.

The author's second institution had been missed in the original article.

The correct author's institutions should be written as above.

The original article was published in Horticulture, Environment, and Biotechnology, Vol. 51, No. 5 (October, 2010). 